\title{
Evidence for an Antiviral Effect of Nitric Oxide Inhibition of Herpes Simplex Virus Type 1 Replication
}

Kenneth D. Croen

Infectious Diseases Division, Department of Internal Medicine, University of Cincinnati College of Medicine, Cincinnati, Ohio 45267-0560

\begin{abstract}
Nitric oxide (NO) has antimicrobial activity against a wide spectrum of infectious pathogens, but an antiviral effect has not been reported. The impact of NO, from endogenous and exogenous sources, on herpes simplex virus type 1 (HSV 1 ) replication was studied in vitro. HSV 1 replication in RAW 264.7 macrophages was reduced 1,806 -fold in monolayers induced to make NO by activation with $\gamma$ IFN and LPS. A competitive and a noncompetitive inhibitor of nitric oxide synthetase substantially reduced the antiviral effect of activated RAW macrophages. $S$-nitroso-L-acetyl penicillamine (SNAP) is a donor of NO and was added to the media of infected monolayers to assess the antiviral properties of NO in the absence of $\gamma$ IFN and LPS. A single dose of $S$-nitroso-L-acetyl penicillamine $3 \mathrm{~h}$ after infection inhibited HSV 1 replication in Vero, HEp2, and RAW 264.7 cells in a dose-dependent manner. Neither virucidal nor cytocidal effects of NO were observed under conditions that inhibited HSV 1 replication. Nitric oxide had inhibitory effects, comparable to that of $\gamma$ IFN / LPS, on protein and DNA synthesis as well as on cell replication. This report demonstrates that, among its diverse properties, NO has an antiviral effect. (J. Clin. Invest. 1993.91:2446-2452.) Key words: nitric oxide $\bullet$ herpes simplex virus $\bullet$ antiviral $\bullet S$-nitroso-L-acetyl penicillamine
\end{abstract}

\section{Introduction}

Herpes simplex viruses (HSV) ${ }^{1}$ types 1 and 2 are extremely prevalent infections of mankind. Primary infection at the site of inoculation is accompanied by infection in the corresponding sensory and autonomic ganglia where latent infections are established. These dormant foci serve as reservoirs for future reactivation infections with $\mathrm{HSV}(1,2)$. Although HSV encodes many genes that contribute to its neuropathogenesis (3, 4 ), the host response has a marked influence on the outcome of wild-type infections. Our understanding of the viral-host interactions that orchestrate the downregulation of lytic infections,

Address correspondence to Dr. Kenneth D. Croen, Infectious Diseases Division, ML 560, Department of Internal Medicine, University of Cincinnati College of Medicine, Cincinnati, OH 45267-0560.

Received for publication 7 October 1992 and in revised form 26 January 1993.

1. Abbreviations used in this paper: DPI, diphenylenediodonium; HSV, herpes simplex virus; M $\phi$, macrophage; L-NMMA, $N^{\mathrm{G}}$-monomethyl-L-arginine; NO, nitric oxide; NOS, NO synthetase; pfu, plaqueforming units; SNAP, $S$-nitroso-L-acetyl penicillamine.

J. Clin. Invest.

(C) The American Society for Clinical Investigation, Inc. 0021-9738/93/06/2446/07 \$2.00

Volume 91, June 1993, 2446-2452 prevent widespread dissemination, and promote the latent state, is incomplete.

Both innate and acquired immune responses are fundamental components of a successful host response to HSV infection. Impaired cellular immune function predisposes to severe primary and recurrent $\mathrm{HSV}$ infections (1). The humoral immune response to HSV facilitates antibody-dependent cell-mediated cytotoxicity and neutralizes cell-free virions with both type-specific and cross-reacting antibodies $(5,6)$. Macrophages and natural killer cells are primary mediators of innate host defense mechanisms. Defects in the ability of these leukocytes to destroy cells productively infected with HSV contributes to the overwhelming infection that is characteristic of HSV infection in neonates (7-9). Other nonspecific host responses to infection, in particular the production of interleukin 2 , tumor necrosis factor- $\alpha$, and interferons, augment the protective functions of macrophages and natural killer cells, and may act directly on infected cells to suppress HSV infection (10-12).

Nitric oxide (NO) is a free radical gaseous molecule that is a mediator of vital physiologic functions, including host defense (13-16). Many cell types are able to produce NO through the enzymatic conversion of $\mathrm{L}$-arginine to $\mathrm{L}$-citrulline by nitric oxide synthetase (NOS). Neurons, endothelial cells, and macrophages are the best characterized sources of NO. From these sites of production, NO modulates neuronal function, regulates vasomotor tone, and is involved in host responses to infection (13-16). NO and related reactive nitrogen intermediates exert microbistatic and microbicidal effects against a variety of pathogens, including protozoans, flukes, fungi, and bacteria (16-21). To date, however, antiviral properties of NO have not been described. The purpose of these studies was to determine whether NO inhibits HSV 1 replication in vitro.

\section{Methods}

Cells and viruses. The RAW 264.7 cell line (TIB 71; American Type Culture Collection, Rockville, MD) is a murine macrophage transformed with the Abelson leukemia virus that produces NO when stimulated with murine $\gamma \mathrm{IFN}$ and/or LPS. These cells were maintained in DMEM (high glucose) supplemented with $10 \%$ heat denatured fetal calf serum (Hyclone Laboratories Inc., Logan, UT), penicillin G ( 100 $\mathrm{U} / \mathrm{ml}$ ), and streptomycin $(100 \mu \mathrm{g} / \mathrm{ml})$. Vero cells (African green monkey kidney) and HEp2 cells (human laryngeal epidermoid carcinoma) were maintained in a 1:1 mixture of DMEM and medium 199 with $10 \%$ heat denatured bovine calf serum (Sigma Immunochemicals, St. Louis, MO) and Pen/Strep ( $100 \mathrm{U} / \mathrm{ml} ; 100 \mu \mathrm{g} / \mathrm{ml}$ ). Stocks of HSV 1 strain 17 syn + (kindly provided by J. Subak-Sharpe, University of Glasgow) were prepared in both Vero cells and RAW cells with final titers of 8 and $3 \times 10^{8}$ plaque-forming units $(\mathrm{pfu}) / \mathrm{ml}$, respectively.

Reagents. $S$-nitroso-L-acetyl penicillamine (SNAP) is a nitrosylated compound prepared by the method of Field et al. from L-acetyl penicillamine and sodium nitrite (Sigma Immunochemicals) (22). In an aqueous solution, SNAP releases NO with a half-life of $\sim 4 \mathrm{~h}(23)$. 
SNAP and penicillamine were stored in a desiccator at $4^{\circ} \mathrm{C}$ and were added to prewarmed media immediately before being placed on cells. Escherichia coli LPS and L-arginine were obtained from Sigma Immunochemicals. Recombinant murine and human $\gamma$ IFN were obtained from Boehringer Mannheim Corp., Indianapolis, IN. Inhibitors of NOS included a competitive inhibitor, $N^{\mathrm{G}}$-monomethyl-L-arginine ( $\mathrm{L}$ NMMA) (Calbiochem-Novabiochem Corp., La Jolla, CA), and an irreversible inhibitor, diphenylenediodonium (DPI) (a gift of A. Cross, Scripps Clinic) $(13,24)$.

Nitrite determinations. Nitrite is a stable compound produced by the reaction of NO with water and oxygen and its accumulation in culture media reflects the amount of NO produced. The concentration of nitrite was determined by mixing equal volumes $(100 \mu \mathrm{l})$ of the sample with Griess reagent ( $0.5 \%$ sulfanilamide, $2.5 \%$ phosphoric acid, $0.05 \%$ napthylethylene diamine) in a 96 -well microtiter plate (25). The OD at a wavelength of $550 \mathrm{~nm}$ was measured on a microplate reader (Molecular Devices Corp., Menlo Park, CA). A range of dilutions of sodium nitrite was used to generate a standard curve with each assay. Medium 199 without phenol red was used in all experiments in which nitrite determinations were made.

Viral infection and titrations. Confluent monolayers of the indicated cell lines in 12-well plates were inoculated with $0.1 \mathrm{pfu} /$ cell of HSV 1 . Virus was adsorbed for $1 \mathrm{~h}$ at room temperature before unadsorbed virus was removed and $1 \mathrm{ml}$ fresh media was added. The media was supplemented with additional reagents as indicated. Infections were terminated by scraping each monolayer into $1 \mathrm{ml}$ of fresh media and freezing at $-70^{\circ} \mathrm{C}$. Intracellular virus was released from infected cells by three freeze/thaw cycles, spun at low speed for $30 \mathrm{~s}$ to remove cellular debris, and the supernatant was titered on Vero cell monolayers in the presence of $1 \%$ human immunoglobulin (Baxter Healthcare Corp., Hyland Division, Glendale, CA). After a 72-h incubation, plates were stained with crystal violet and plaques were counted.

The absolute viral titers varied from one experimental series to another. Therefore, data from multiple experiments (each with twosix replicates) performed on different days were normalized by calculating the "fold reduction" in viral titer (mean control titer $\div$ mean titer of $\gamma$ IFN/LPS or SNAP-treated samples). Statistical comparisons were performed using the logarithm of the viral titers.

Assay for virucidal activity. Media containing $10^{6} \mathrm{pfu} / \mathrm{ml}$ of $\mathrm{HSV} 1$ was incubated at $37^{\circ} \mathrm{C}$ with SNAP $(500 \mu \mathrm{M})$, L-acetyl penicillamine $(500 \mu \mathrm{M}), 10 \%$ ethanol, $\gamma \mathrm{IFN}$ and LPS $(100 \mathrm{U} / \mathrm{ml}$ and $100 \mathrm{ng} / \mathrm{ml}$, respectively), or media alone. Aliquots were removed over a 5 -h period and diluted 100-10,000 fold for quantitation of remaining infectious viral particles on Vero cell monolayers.

Cell viability. The inability of injured or dead cells to exclude ethidium bromide $(1 \mu \mathrm{g} / \mathrm{ml})$ was monitored to assess the contribution of NO-induced cytotoxicity to the reduction in HSV 1 replication (26). Dead cells were quantified with ultraviolet light microscopy. The titer of intracellular virus was not affected by staining with ethidium bromide prior to harvesting the monolayer.

Metabolic studies. Incorporation of $\left[{ }^{3} \mathrm{H}\right]$ thymidine, $\left[{ }^{3} \mathrm{H}\right]$ leucine, and the kinetics of cell replication were investigated in the presence or absence of NO. Confluent monolayers of Vero and RAW macrophages $(\mathbf{M} \phi)$ in microtiter plates were incubated with $\left[{ }^{3} \mathrm{H}\right]$ thymidine $(0.5$ $\mu \mathrm{Ci} /$ well, sp act $84.9 \mathrm{Ci} / \mathrm{mmol}$; New England Nuclear, Boston, MA) or $\left[{ }^{3} \mathrm{H}\right]$ leucine $(1 \mu \mathrm{Ci} /$ well, specific activity $145 \mathrm{Ci} / \mathrm{mmol}$; New England Nuclear) for $24 \mathrm{~h}$. Both cell types were treated with SNAP (250 $\mu \mathrm{M})$, penicillamine $(250 \mu \mathrm{M})$, or media alone. RAW M $\phi$ were alternatively incubated with $\gamma$ IFN/LPS. Reagents were added immediately after ${ }^{3} \mathrm{H}$ ( $\gamma$ IFN/LPS) or $3 \mathrm{~h}$ later (SNAP, penicillamine) to mimic the conditions used in the viral replication studies. After a 24-h incubation with ${ }^{3} \mathrm{H}$, the supernatant was removed and replaced with water to lyse the cells, and the contents of each well was transferred to glass fiber filters with a semiautomated cell harvester. The quantity of ${ }^{3} \mathrm{H}$ incorporated into DNA or protein was determined in a liquid scintillation counter. Each experiment included three or four replicates per treatment.
Cell replication was studied in the presence of SNAP, penicillamine, or media alone by performing cell counts in a hemocytometer on trypsinized monolayers 24,48 , and $72 \mathrm{~h}$ after plating Vero and RAW cells in low density $\left(1 \times 10^{5}\right.$ cells $/$ well $)$. The effect of $\gamma \mathrm{IFN}(50 \mathrm{U} / \mathrm{ml})$ and LPS $(50 \mathrm{ng} / \mathrm{ml})$ on RAW M $\phi$ replication also was investigated. In all cases, reagents were removed from the cell culture media after the first 24-h incubation.

\section{Results}

\section{$H S V 1$ replication and nitric oxide production in $R A W$ $264.7 M \phi$}

As a first step to determine whether NO inhibits HSV 1 replication, the ability of HSV 1 to replicate in a cell line that can be stimulated to produce NO was investigated. The RAW 264.7 $\mathrm{M} \phi$ has been used widely in studies of inducible NO production and, therefore, was selected for the studies that follow.

Confluent monolayers of RAW M $\phi$ were inoculated with HSV 1 (moi 0.1 ) and then incubated in medium 199 with or without $\gamma \mathrm{IFN}(50 \mathrm{U} / \mathrm{ml})$ and LPS $(50 \mathrm{ng} / \mathrm{ml})$. The results of eight experiments are summarized in Table I. HSV 1 replicated to high titer within $24 \mathrm{~h}$ of inoculation in unstimulated control monolayers. Minimal quantities of NO were produced in these monolayers. In contrast, viral replication was dramatically decreased in monolayers stimulated with $\gamma$ IFN/LPS, coinciding with the production of an abundant quantity of NO.

\section{The effect of L-NMMA on HSV 1 replication in activated $M \phi$}

In the next series of experiments, inhibitors of NOS were used to determine if NO or other reactive nitrogen intermediates contributed to the inhibition of HSV 1 replication in activated M $\phi$. After inoculation of RAW M $\phi$ with HSV 1 (moi 0.1), the monolayers were activated with $\gamma$ IFN/LPS in the presence or absence of the competitive inhibitor, L-NMMA. As shown in Fig. 1, L-NMMA substantially reduced the ability of activated M $\phi$ to inhibit HSV 1 replication. Treatment with L-NMMA coincided with an $81 \%$ decrease in nitrite production by activated $\mathbf{M} \phi$.

A high concentration of $\mathrm{L}$-arginine should compete with L-NMMA and partially reverse its effect on NO production and viral replication (13). In Fig. 2, the effect of L-NMMA with and without additional L-arginine is shown. RAW M $\phi$ were inoculated with HSV 1 (moi 0.1 ) and then activated with $\gamma \mathrm{IFN}(50 \mathrm{U} / \mathrm{ml})$ and LPS $(50 \mathrm{ng} / \mathrm{ml})$ as indicated. L-NMMA $(250 \mu \mathrm{M})$ and $\mathrm{L}$-arginine $(1,000 \mu \mathrm{M})$ also were added immediately after inoculation. The effects of $250 \mu \mathrm{M}$ L-NMMA on HSV 1 replication and nitrite production in cultures of acti-

Table I. HSV 1 Infection of RAW M ; The Effect of $\gamma I F N / L P S$

\begin{tabular}{lcc}
\hline & Control & $\gamma$ IFN/LPS \\
\hline Mean titer \pm SEM (pfu/well) & $1.3 \pm 0.2 \times 10^{7}$ & $7.2 \pm 1.6 \times 10^{38}$ \\
Fold reduction in viral titer & - & 1,806 \\
{$\left[\mathrm{NO}_{2}-\right] \pm \mathrm{SEM}^{\ddagger}$} & $0.8 \pm 0.1 \mu \mathrm{M}$ & $48 \pm 2 \mu \mathrm{M}$ \\
\hline
\end{tabular}

* $50 \mathrm{U} / \mathrm{ml} \gamma \mathrm{IFN}$ and $50 \mathrm{ng} / \mathrm{ml} \mathrm{LPS}$ added immediately after inoculation.

$¥ 24 \mathrm{~h}$ after inoculation.

${ }^{\S} P=0.0001$ by paired $t$ test. 

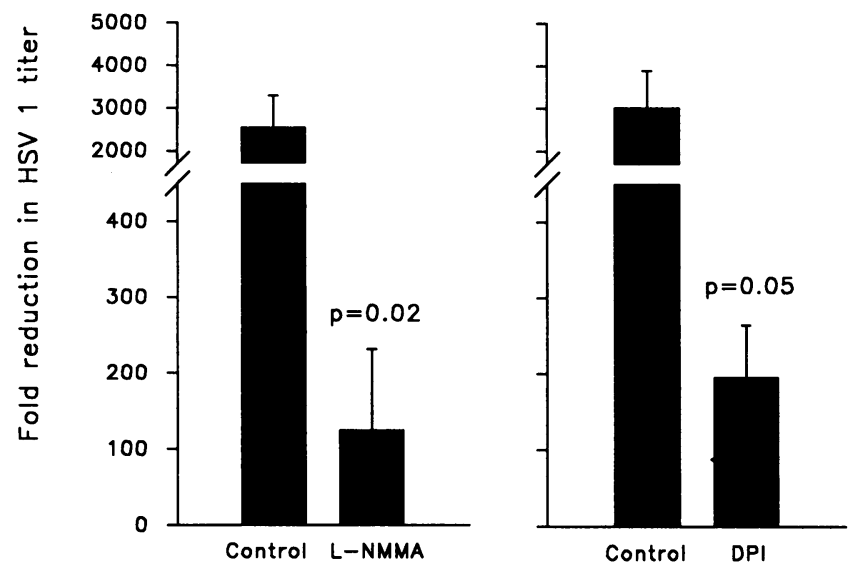

Figure 1. Inhibitors of NOS reverse the antiviral effect in RAW M $\phi$ activated with $\gamma$ IFN and LPS. Confluent monolayers of RAW M $\phi$ were inoculated with HSV 1 ( moi 0.1). Immediately after inoculation, half of the monolayers were supplemented with $\gamma \mathrm{IFN}(50 \mathrm{U} /$ $\mathrm{ml})$ and LPS $(50 \mathrm{ng} / \mathrm{ml})$. L-NMMA $(250 \mu \mathrm{M})$ or DPI ( $100-200$ $\mathrm{nM}$ ) was added to both activated and unactivated wells concomitant with $\gamma$ IFN/LPS. Viral titers were determined $24 \mathrm{~h}$ after infection. The data are expressed as fold reduction (titer in unactivated wells $\div$ the titer in $\gamma$ IFN/LPS-activated wells) and represent the mean of means ( \pm SEM) from several experiments: L-NMMA (4), DPI (3). Statistical comparisons were performed by a paired $t$ test using differences in the logarithm of control and $\gamma$ IFN/LPS-treated samples.

vated $\mathbf{M} \phi$ were partially reversed by the addition of a fivefold molar excess of L-arginine ( final concentration $1.33 \mathrm{mM}$ ). The degree of inhibition of viral replication in activated $\mathbf{M} \phi$ was reduced from 2,222-fold ( $a$ and $c$ ) in the absence of L-NMMA to 43-fold in its presence ( $d$ and $e$ ). Arginine restored some of the antiviral effect, resulting in a 320 -fold decrease in viral titer in the presence of $\gamma$ IFN/LPS ( $d$ and $f$ ). Similarly, nitrite production was restored by the addition of $L$-arginine. These data suggest that an arginine-dependent pathway contributes to the antiviral state in activated RAW M $\phi$.

Arginine is consumed by NOS in the production of NO, accounting for $\sim 33 \%$ of the metabolism of this amino acid by activated macrophages (17). Because of their extremely high guanine and cytosine (GC) content, HSV proteins incorporate many arginine residues and the virus grows poorly in the absence of this amino acid (27). To determine if arginine depletion by NOS could account for the decline in HSV 1 replication, experiments were performed in media containing standard $(333 \mu \mathrm{M})$ or high $(1,333 \mu \mathrm{M})$ concentrations of L-arginine with or without $\gamma$ IFN and LPS. Supplemental arginine had no effect on either the viral titer or nitrite concentration $24 \mathrm{~h}$ after infection (data not shown). Therefore, the inhibition of HSV 1 replication in activated $\mathbf{M} \phi$ probably was not caused by consumption of L-arginine by NOS.

Is an alternative arginine-dependent pathway involved in suppressing HSV replication in cells exposed to rIFN and LPS?

Definitive assignment of the antiviral arginine-dependent pathway to the production of NO assumes that other metabolic effects of arginine do not result in the inhibition of HSV 1 replication. To explore the possibility that arginine may be important in other $\gamma$ IFN/LPS induced antiviral mechanisms, HEp2 cells were used which inhibit HSV 1 replication when stimulated with $\gamma$ IFN/LPS but do not yield detectable amounts of nitrite upon stimulation. Monolayers of HEp2 cells were stimulated for $24 \mathrm{~h}$ with human $\gamma \mathrm{IFN}(100 \mathrm{U} / \mathrm{ml})$ and LPS ( $100 \mathrm{ng} / \mathrm{ml})$ in the presence or absence of L-NMMA ( 250 $\mu \mathrm{M})$. Control monolayers were either untreated or incubated with L-NMMA alone. After inoculation with HSV 1, the cells were incubated for 3 or $24 \mathrm{~h}$ in media containing the same reagents as before infection. In two independent experiments, the mean reductions in HSV 1 replication resulting from $\gamma$ IFN/LPS treatment were 115- and 51-fold (mean 83) in the absence of L-NMMA, and 121- and 73-fold (mean 97) in the presence of L-NMMA. If an arginine-dependent pathway was involved in the antiviral state in HEp2 cells exposed to $\gamma$ IFN/ LPS, then an increase in the viral titer and a decrease in the fold reduction of viral replication would have been observed in the presence of L-NMMA. Therefore, evidence for an alternative arginine-dependent pathway that produces an antiviral effect in $\gamma$ IFN/LPS-treated HEp2 cells was not detected.

\section{The effect of DPI on HSV 1 replication in activated $M \phi$}

DPI irreversibly blocks the activity of NOS by binding to FAD and NADPH binding sites on the enzyme (24). Further evi-
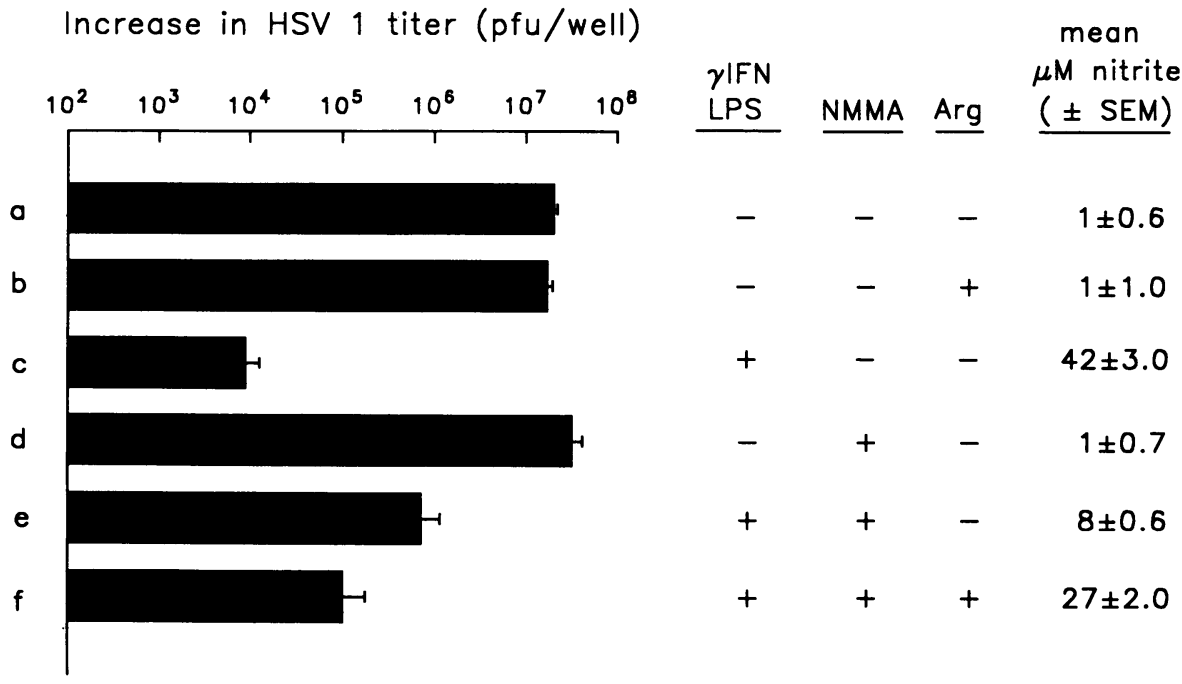

Figure 2. The effect of L-NMMA on HSV 1 replication in RAW M $\phi$; reversal with L-arginine. Confluent monolayers of RAW $\mathrm{M} \phi$ were inoculated with HSV 1 ( moi 0.1) and then activated with $\gamma \mathrm{IFN}(50 \mathrm{U} / \mathrm{ml})$ and LPS ( $50 \mathrm{ng} / \mathrm{ml})$. L-NMMA $(250 \mu \mathrm{M})$ and $L$-arginine $(1,000 \mu \mathrm{M})$ were added immediately after inoculation as indicated. Cells were harvested $24 \mathrm{~h}$ after infection for titration of intracellular HSV. Data represent the mean \pm SEM for three identical experiments. $P<0.03$ for $a$ vs $c, d$ vs $e, d$ vs $f, e$ vs $f$, and $c$ vs $e ; P=0.08$ for $c$ vs $f$ (by two-way ANOVA). 
dence that NO contributes to the antiviral effect in activated RAW M $\phi$ was obtained with this NOS inhibitor. The data in Fig. 1 demonstrate that 100-200 nM DPI reduced the ability of activated $\mathrm{M} \phi$ to inhibit the growth of HSV 1 to a degree comparable to that of L-NMMA. As expected, the addition of 1,000 $\mu \mathrm{M}$ L-arginine to monolayers incubated with $\gamma$ IFN/LPS and DPI did not alter the irreversible effect of DPI (data not shown).

\section{The effect of nitric oxide from an exogenous source on $H S V 1$ replication}

$\gamma$ IFN and LPS induce a wide range of metabolic effects within macrophages that contribute to their ability to inhibit HSV 1 replication $(28,29)$. An exogenous source of $\mathrm{NO}$ eliminates the need for $\gamma$ IFN/LPS and thereby permits a more direct assessment of the potential antiviral effects of NO. Several compounds that release NO (NO donors) have been described $(23,30)$.

SNAP, the nitrosylated form of $\mathrm{L}$-acetyl penicillamine, donates NO when placed in an aqueous solution (23). The effect of this compound on HSV 1 replication was investigated. Confluent monolayers of Vero cells were inoculated with HSV 1 (moi 0.1 ) and, at several times thereafter, freshly prepared solutions of SNAP ( $500 \mu \mathrm{M})$ or media alone were added to the cultures. In three experiments, a greater antiviral effect was consistently observed when SNAP was added to the media $3 \mathrm{~h}$ after inoculation than when added immediately after the 1-h adsorption. The mean fold reductions were $105 \pm 54$ when added at $3 \mathrm{~h}$, and $22 \pm 4.3$ when added at $0 \mathrm{~h}$ (in each case $P$ $<0.02$ vs control; $P=0.06$ comparing fold reduction at $3 \mathrm{~h}$ vs. $0 \mathrm{~h}$; by a paired $t$ test ). SNAP was added $3 \mathrm{~h}$ after inoculation in all subsequent studies.

Dose response studies were performed in RAW M $\phi$, Vero cells, and HEp2 cells infected with HSV 1 ( moi 0.1). As shown in Fig. 3, replication of HSV 1 in each cell line was inhibited by

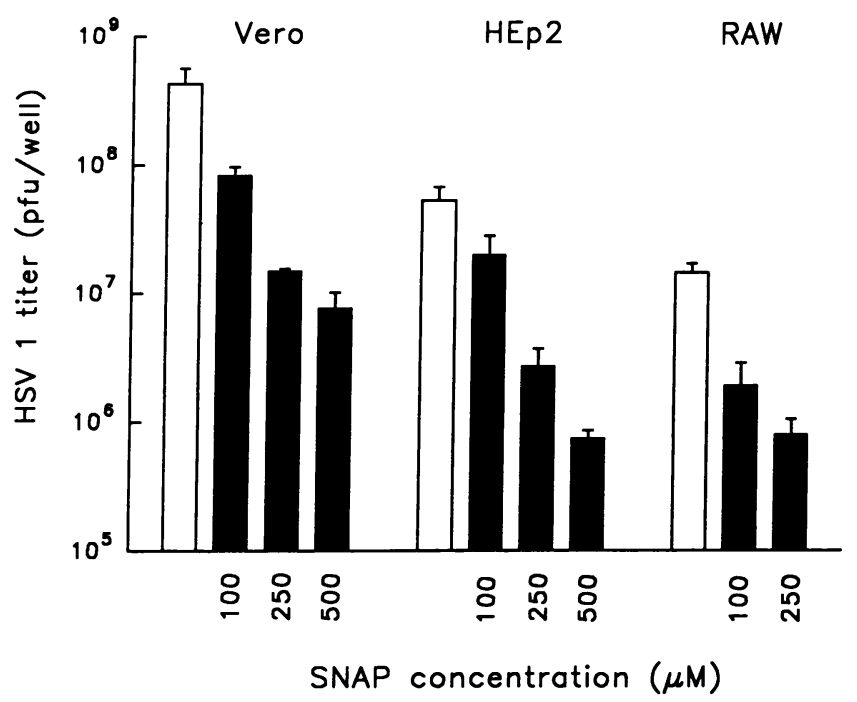

Figure 3. Antiviral effects of SNAP: dose response. Confluent monolayers of Vero, RAW M $\phi$, or HEp2 cells in 12-well plates were inoculated with HSV 1 (moi 0.1 ). $3 \mathrm{~h}$ later, a freshly made solution of SNAP was added to the media to yield the final concentrations indicated. Cells were harvested by scraping $24 \mathrm{~h}$ after infection and intracellular virus was titered on Vero cell monolayers. Each bar represents the mean \pm SEM for triplicate samples.
SNAP in a dose-dependent manner. In comparison to Vero and HEp2 cells, RAW M $\phi$ were more sensitive to the cytotoxic effects of SNAP and a significant decrease in cell viability was observed at a concentration of $500 \mu \mathrm{M}$. Over multiple experiments, $500 \mu \mathrm{M}$ SNAP inhibited HSV 1 replication by a mean of $160 \pm 61$-fold in Vero cells $(n=9)$ and $30 \pm 10$-fold in HEp2 cells $(n=6)$. At $250 \mu \mathrm{M} \mathrm{SNAP,} \mathrm{HSV} 1$ replication was reduced $101 \pm 38$-fold in Vero cells $(n=10)$ and $15 \pm 1$.9-fold in RAW $\mathbf{M} \phi(n=3)$. In each case, the titers of the SNAP-treated monolayers were significantly different from the controls $(P<0.05$ by a paired $t$ test). Penicillamine controls were included in most experiments and, in each case, titers were virtually identical to untreated controls (data not shown).

\section{Potential mechanisms of the antiviral effect of NO}

Studies on the virucidal activity of SNAP and $\gamma I F N / L P S$. The possibility that SNAP or $\gamma$ IFN/LPS mediated their antiviral effects by destroying the infectivity of whole virions was investigated. As shown in Fig. 4, this proved not to be the case. HSV 1 was incubated for $5 \mathrm{~h}$ at $37^{\circ} \mathrm{C}$ in media alone, or media supplemented with SNAP (500 $\mu \mathrm{M})$, L-acetyl penicillamine $(500 \mu \mathrm{M}), \gamma \mathrm{IFN}(100 \mathrm{U} / \mathrm{ml})$ and LPS $(100 \mathrm{ng} / \mathrm{ml})$, or $10 \%$ ethanol. While $10 \%$ ethanol was predictably virucidal, none of the other reagents caused an acceleration in the loss of viral infectivity.

Cytotoxicity of nitric oxide. The antiviral activity associated with NO also could be secondary to its well-recognized cytotoxic properties (31). Several approaches were taken to evaluate the effects of NO on cellular metabolism and viability. The synthetic functions of Vero cells and RAW M $\phi$ were quantified

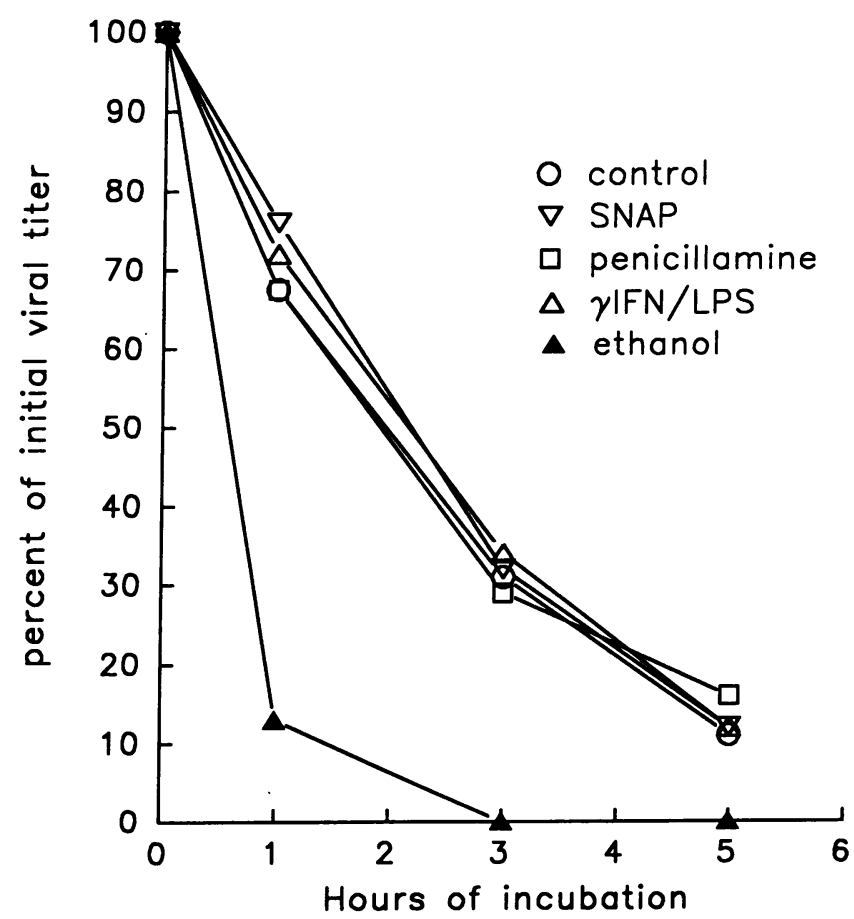

Figure 4. Assay for virucidal activity. HSV $1\left(10^{6} \mathrm{pfu}\right)$ was incubated with SNAP $(500 \mu \mathrm{M}), \mathrm{L}$-acetyl penicillamine $(500 \mu \mathrm{M}), \gamma \mathrm{IFN}(100$ $\mathrm{U} / \mathrm{ml})$ and $\mathrm{LPS}(100 \mathrm{ng} / \mathrm{ml}), 10 \%$ ethanol, or media alone. At the indicated time points, $10^{4} \mathrm{pfu}$ of input virus was removed, diluted to $1 \mathrm{ml}$ with media, and titered on a Vero cell monolayer. Each point represents the mean of duplicate samples. 
by monitoring their ability to incorporate $\left[{ }^{3} \mathrm{H}\right]$ leucine and $\left[{ }^{3} \mathrm{H}\right]$ thymidine in the presence or absence of NO. As shown in Table II, SNAP ( $250 \mu \mathrm{M})$ inhibited protein synthesis in both Vero and RAW cells and DNA synthesis in RAW cells. The metabolic activity of RAW M $\phi$ stimulated with $\gamma$ IFN/LPS was impaired to a similar degree and was partially reversed by L-NMMA.

Another manifestation of the cytotoxicity of NO that may be relevant to its antiviral activity is its effect on cell division (31). Vero cells were plated at low density $\left(1 \times 10^{5}\right.$ cells $/$ well of a 12-well plate) and incubated with or without SNAP. After $24 \mathrm{~h}$, the monolayers were trypsinized and the cell density quantified in a hemocytometer. SNAP-treated wells contained $48 \%(250 \mu \mathrm{M})$ and $60 \%(500 \mu \mathrm{M})$ fewer cells than the untreated controls ( $n=6$ for each group). However, cell viability determined by ethidium bromide staining prior to scraping was not altered by SNAP ( $>99 \%$ viable in all wells). Fresh media without SNAP was placed on the remaining wells after the 24-h incubation and cell replication was monitored. Over the subsequent $48 \mathrm{~h}$, the cell density in SNAP-treated wells approached that of untreated controls ( $87 \%$ of controls). Similar results were obtained with RAW M $\phi$ and HEp2 cells incubated with SNAP as well as RAW M $\phi$ activated with $\gamma \operatorname{IFN}(50 \mathrm{U} / \mathrm{ml})$ and LPS ( $50 \mathrm{ng} / \mathrm{ml}$ ). The addition of $250 \mu \mathrm{M}$ L-NMMA to activated RAW $M \phi$ did not alleviate the inhibition of cell replication induced by $\gamma$ IFN/LPS (data not shown). Cell replication in media containing $500 \mu \mathrm{M}$ penicillamine was almost identical to the untreated control.

In addition to these metabolic studies, the impact of NO on cell viability was investigated. The viability of uninfected and HSV 1-infected RAW M $\phi$ was monitored by ethidium bromide exclusion in the presence or absence of $\gamma$ IFN and LPS. 24 $h$ after activation of uninfected RAW cells, viability was identical to that of unactivated controls (96-99\%). The media containing $\gamma$ IFN and LPS was replaced with fresh media alone after $24 \mathrm{~h}$. More than $98 \%$ of activated and unactivated RAW M $\phi$ remained viable 48 and $72 \mathrm{~h}$ after activation. A similar result was obtained in HSV 1 -infected monolayers activated with $\gamma$ IFN and LPS immediately after inoculation (moi 0.1). Both 24 and $36 \mathrm{~h}$ after infection, ethidium bromide staining revealed almost identical viability of activated and unactivated monolayers: $94 \%$ (both activated and unactivated) at $24 \mathrm{~h}$; $85 \%$ (activated) and $82 \%$ (unactivated) at $36 \mathrm{~h}(n=4$ for each

Table II. Protein and DNA Synthesis in the Presence of NO

\begin{tabular}{llcc}
\hline & & \multicolumn{2}{c}{ Percentage of control $( \pm \text { SEM })^{*}$} \\
\cline { 3 - 4 } Cell line & Treatment $^{*}$ & {$\left[{ }^{3} \mathrm{H}\right]$ leucine } & {$\left[^{3} \mathrm{H}\right]$ thymidine } \\
\hline \multirow{2}{*}{ Vero } & SNAP & $72 \pm 4$ & $102 \pm 12$ \\
& Pen & $102 \pm 2$ & $114 \pm 18$ \\
& SNAP M $\phi$ & $63 \pm 12$ & $55 \pm 11$ \\
& Pen & $76 \pm 2$ & $93 \pm 4$ \\
& IFN/LPS & $75 \pm 2$ & $49 \pm 3$ \\
& L-NMMA & $85 \pm 2$ & $98 \pm 17$ \\
& IFN/LPS + & $83 \pm 8$ & $65 \pm 5$ \\
& L-NMMA & & \\
& & & \\
\end{tabular}

\footnotetext{
* Mean of two-four experiments.

‡ Concentrations: SNAP and penicillamine $(250 \mu \mathrm{M}) ; \gamma \mathrm{IFN}(50 \mathrm{U} /$ $\mathrm{ml}) ;$ LPS (50 ng/ml); L-NMMA (250 $\mu \mathrm{M})$.
}

group at each time point). The 1,806 -fold reduction in viral titer from activated RAW M $\phi$ (Table I) therefore, cannot be explained by an excess of cell death in these monolayers.

Several observations suggest that cytocidal properties of SNAP did not contribute to its antiviral effect. First, the viability of each cell line (Vero, HEp2, and RAW M $\phi$ ) was maintained (>99\%) for up to $48 \mathrm{~h}$ after a 24-h incubation with SNAP ( $500 \mu \mathrm{M}$ for Vero and HEp2; $250 \mu \mathrm{M}$ for RAW M $\phi$ ). Secondly, the viability of infected monolayers also was unaffected by the presence of SNAP. $24 \mathrm{~h}$ after infection, $98 \%$ of SNAP-treated (500 $\mu \mathrm{M})$ Vero cells excluded ethidium bromide as opposed to $99 \%$ of untreated controls. Finally, the antiviral effect was greater when SNAP was added $3 \mathrm{~h}$ after inoculation rather than when it was added immediately afterward. If a cytotoxic effect of NO was responsible for the reduction in HSV 1 replication, then a more potent inhibitory effect would have been likely with the addition of SNAP immediately after inoculation.

\section{Discussion}

Nitric oxide is being recognized increasingly as an important component of the host response to infection (16-21). NO modulates immune responses by mediating the regulation of lymphocyte proliferation by suppressor macrophages (32). Furthermore, it influences local inflammatory reactions by altering adherence of neutrophils to endothelial surfaces (33). When $\mathbf{M} \phi$, endothelial cells, and smooth muscle cells are stimulated to overproduce NO by circulating endotoxin, the physiologic disruptions that are characteristic of septic shock may ensue (34). In addition, NO and other reactive nitrogen intermediates have direct microbistatic and microbicidal activities against a variety of pathogens (16-21). In this report, evidence for an antiviral effect of NO is provided by its ability to inhibit HSV 1 replication.

The transformed murine macrophage cell line, RAW 264.7, is very permissive for HSV 1 replication until activated by $\gamma$ IFN and LPS ( Table I). Two functionally different inhibitors of NOS, L-NMMA and DPI, reduced the ability of activated RAW M $\phi$ to suppress HSV 1 replication (Fig. 1). The fact that neither of these inhibitors completely reversed the antiviral state in RAW M $\phi$ induced with $\gamma$ IFN/LPS is consistent with the activation of other known inhibitors of HSV 1 in these cells including TNF $\alpha, 2^{\prime} 5^{\prime}$-oligoadenylate synthetase, and the P1 / eIF-2 $\alpha$ protein kinase (28). When NO was also present in this pool of inhibitors, HSV 1 replication was more completely inhibited (Fig. 2).

L-NMMA and DPI are not specific inhibitors of the nitric oxide synthetase. Arginine-dependent pathways other than the one that produces NO may be inhibited by L-NMMA and could be responsible for the antiviral effect in activated RAW $\mathrm{M} \phi$. However, evidence for an alternative antiviral argininedependent pathway in HEp2 cells treated with $\gamma$ IFN/LPS was not observed. Of course, this observation does not exclude such a pathway in an activated murine macrophage.

An exogenous source of NO facilitated a more direct assessment of its effect on HSV 1 replication. In the absence of $\gamma$ IFN and LPS, antiviral activity was observed in several cell lines exposed to SNAP (Fig. 3). Despite a relatively short half-life (4 $\mathrm{h}$ ), a single administration of SNAP $3 \mathrm{~h}$ after infection reduced HSV 1 replication in each of three cell lines by 93-99\%. 
Although a direct virucidal effect of SNAP or $\gamma$ IFN/LPS was not observed, the cytotoxic effects of NO probably contribute to its antiviral activity. Interference with the metabolism of cells in tissue culture produced a decrease in protein and DNA synthesis as well as a decrease in the rate of cell division. It is important to note that $\gamma$ IFN/LPS treatment of RAW M $\phi$ yielded comparable results, even in the presence of L-NMMA. Therefore, although the metabolic effects of NO may contribute to its antiviral activity, this mechanism also is likely to account for some of the antiviral properties of other host-response mediators such as interferon.

Cell viability was not impaired by $\mathrm{NO}$ at the concentrations and durations of treatment used in this study. Interestingly, the viability of infected monolayers was unaltered by the addition of SNAP (or in activated RAW M $\phi$ ) despite the reduction in HSV 1 replication. Enhanced cytotoxicity of NO in the presence of HSV infection, or preserved cytopathic behavior of the virus despite a decline in the number of infectious particles, may account for this effect.

Cytostasis is a well-recognized effect of NO and was observed with each of the cell lines employed in these studies ( 16 , $17,21,31)$. Previous studies suggest that HSV replication may be impaired in growth-arrested cells, particularly when certain viral genes are defective, such as ICPO or ribonucleotide reductase $(35,36)$. The latter enzyme accounts, in large part, for the dramatic rise in the intracellular pool of deoxynucleotides observed during a lytic HSV infection (37). NO typically interacts with iron-containing proteins and, in the case of ribonucleotide reductase, interferes with its enzymatic function. Inhibition of several cellular ribonucleotide reductases by NO has been described and may account for some of its cytostatic properties (38). Like its cellular counterpart, the ribonucleotide reductase encoded by HSV has an iron moiety and is likely to be inhibited by NO. Although the HSV-encoded ribonucleotide reductase is not essential for viral replication in vitro, it is necessary under conditions where the intracellular pool of deoxynucleotides is in limited supply $(36,39,40)$. Inhibition of the cellular and viral ribonucleotide reductase might explain the sensitivity of HSV 1 to NO.

One of the most thoroughly studied effects of NO is its ability to activate the heme-containing enzyme, guanylate cyclase $(41,42)$. Interaction of NO with the cytosolic form of guanylate cyclase stimulates the production of cGMP which, in turn, mediates many well characterized intracellular events $(13-15,41,42)$. Little is known about the effect of cGMP on HSV replication. Elevations in cGMP delay reactivation of HSV 1 from its latent state in explanted murine sensory ganglia while cAMP accelerates reactivation $(43,44)$. The role of cGMP in HSV-infected sensory neurons will need to be defined to more completely understand the role of NO in the pathogenesis of HSV infections.

Viral, immune, and cellular factors may all contribute to the downregulation of lytic HSV 1 infections. Recent evidence suggests that the presence of the viral latency-associated transcripts may enhance the ability of HSV 1 to establish a latent infection in trigeminal ganglia (45). The viral ribonucleotide reductase appears to be required for HSV to lytically infect and reactivate from sensory neurons $(39,40)$. However, studies with engineered viral mutants deficient in latency-associated transcripts, ribonucleotide reductase, as well as many other loci demonstrate that these genes are not essential for the establish- ment of latency (40, 45-47). Host immune responses play an important role in containing acute infections and probably help to prevent the clinical expression of HSV reactivations (1). However, even severe immune defects do not necessarily precipitate a recurrence of $\mathrm{HSV}$ infection. Therefore, neuronal characteristics are likely to be essential in modulating the status of HSV infection.

Nitric oxide seems well suited to play a role in the pathogenesis of HSV infections. HSV may come in contact with NO by infecting neurons that contain the constitutive form of NOS. This enzyme is found in a few percent of neurons in normal sensory ganglia (48). However, up to $45 \%$ of neurons in rat dorsal root ganglia can express the neuronal NOS mRNA for at least 2 mo after nerve injury (49). In addition, HSV may be exposed to cells with inducible NOS including resident cells in the nervous system (i.e., astrocytes, endothelial cells, and perhaps others) or infiltrating leukocytes (50). As an endogenous inhibitor of ribonucleotide reductase, NO may contribute significantly to the balance that exists between the virus and its host neuron.

An understanding of how NO affects interactions between HSV and the host may have direct applications to other viruses. For example, other herpes viruses, including varicellazoster virus and EBV, have ribonucleotide reductase genes that may be targets for NO. Furthermore, other viruses that reside in cells of the immune and nervous systems (i.e., HIV, cytomegalovirus) may be subject to the influences of NO. Therefore, defining the influence that NO has on HSV 1 infection may provide useful insights into the pathogenesis of other viral infections.

\section{Acknowledgments}

The author is grateful for the expert technical assistance of Donna Thee. The assistance of Dr. Scott E. Michaels in performing the statistical analyses was greatly appreciated. The author also thanks Charlotte Kratt for technical assistance, as well as Drs. Simon Newman, George Deepe, Francisco Gomez, Kenneth Radack, Ward Bullock, Solomon Snyder, and Donald Granger for helpful discussions.

This work was supported by the Pfizer Scholars Program for New Faculty.

\section{References}

1. Corey, L., and P. G. Spear. 1986. Infections with herpes simplex viruses. $N$. Engl. J. Med. 314:686-691, 749-757.

2. Stevens, J. G. 1989. Human herpesviruses: a consideration of the latent state. Microbiol. Rev. 53:318-332.

3. Thompson, R. L., G. B. Devi-Rao, E. K. Wagner, and J. G. Stevens. 1985. Rescue of a herpes simplex virus type 1 neurovirulence function with a cloned DNA fragment. J. Virol. 55:504-508.

4. Chou, J., E. R. Kern, R. J. Whitley, and B. Roizman. 1990. Mapping of herpes simplex virus-1 neurovirulence to $\gamma_{1} 34.5$, a gene nonessential for growth in culture. Science (Wash. DC). 250:1262-1266.

5. Kohl, S. 1991. Role of antibody-dependent cellular cytotoxicity in defence against herpes simplex virus infections. Rev. Infect. Dis. 13:108-114.

6. Mertz, G. J., J. Benedetti, R. Ashley, S. A. Selke, and L. Corey. 1992. Risk factors for the sexual transmission of genital herpes. Ann. Intern. Med. 116:197202.

7. Kohl, S., L. S. Loo, D. B. Drath, and P. Cox. 1989. Interleukin-2 protects neonatal mice from lethal herpes simplex virus infection: a macrophage mediated, $\gamma$ interferon-induced mechanism. J. Infect. Dis. 159:239-247.

8. Hayward, A., M. Laszlo, and A. Vafai. 1989. Human newborn natural killer cell responses to activation by monoclonal antibodies: effect of culture with herpes simplex virus. J. Immunol. 142:1139-1143.

9. Oh, S. H., B. Gonik, S. B. Greenberg, and S. Kohl. 1986. Enhancement of 
human neonatal natural killer cytotoxicity to herpes simplex virus with use of recombinant human interferons: lack of neonatal response to $\gamma$ interferon. $J$. Infect. Dis. 153:791-793.

10. Kohl, S. 1990. Protection against murine neonatal herpes simplex virus infection by lymphokine-treated human leukocytes. J. Immunol. 144:307-312.

11. Feduchi, E., M. A. Alonso, and L. Carrasco. 1989. Human gamma interferon and tumor necrosis factor exert a synergistic blockade on the replication of herpes simplex virus. J. Virol. 63:1354-1359.

12. Grace, H., W. Wong, and D. V. Goeddel. 1986. Tumor necrosis factors $\alpha$ and $\beta$ inhibit virus replication and synergize with interferons. Nature (Lond.). 323:819-821.

13. Moncada, S., R. M. J. Palmer, and E. A. Higgs. 1991. Nitric oxide: physiology, pathophysiology, and pharmacology. Pharmacol. Rev. 43:109-142.

14. Bredt, D. S., and S. H. Snyder. 1992. Nitric oxide, a novel neuronal messenger. Neuron. 8:3-11.

15. Garthwaite, J. 1991. Glutamate, nitric oxide and cell-cell signalling in the nervous system. Trends Neurosci. 14:60-67.

16. Nathan, C. F., and J. B. Hibbs. 1991. Role of nitric oxide synthesis in macrophage antimicrobial activity. Curr. Opin. Immunol. 3:65-70.

17. Granger, D. L., J. B. Hibbs, J. R. Perfect, and D. T. Durack. 1988. Specific amino acid (L-arginine) requirement for the microbiostatic activity of murine macrophages. J. Clin. Invest. 81:1129-1136.

18. James, S. L., and J. Glavin. 1989. Murine macrophage cytotoxicity against schistosomula of Schistosoma mansoni involves arginine-dependent production of reactive nitrogen intermediates. J. Immunol. 143:4208-4212.

19. Liew, F. Y., S. Millott, C. Parkinson, R. M. J. Palmer, and S. Moncada. 1990. Macrophage killing of Leishmania parasite in vivo is mediated by nitric oxide from L-arginine. J. Immunol. 144:4794-4797.

20. Denis, M. 1991. Interferon-gamma-treated murine macrophages inhibit growth of tubercle bacilli via the generation of reactive nitrogen intermediates. Cell. Immunol. 132:150-157.

21. Alspaugh, J. A., and D. L. Granger. 1991. Inhibition of Cryptococcus neoformans replication by nitrogen oxides supports the role of these molecules as effectors of macrophage-mediated cytostasis. Infect. Immun. 59:2291-2296.

22. Field, L., R. V. Dilts, R. Ravichandran, P. G. Lenhert, and G. E. Carnahan. 1978. An unusually stable thionitrite from $\mathrm{N}$-acetyl-D,L-penicillamine; $\mathrm{x}$ ray crystal and molecular structure of 2-(acetylamino)-2-carboxy-1,1-dimethylethyl thionitrite. J. Chem. Soc. Perkin Trans. I. 249-250.

23. Ignarro, L. J., H. Lippton, J. C. Edwards, W. H. Baricos, A. L. Hyman, P. J. Kadowitz, and C. A. Gruetter. 1981. Mechanism of vascular smooth muscle relaxation by organic nitrates, nitrites, nitroprusside and nitric oxide: evidence for the involvement of S-nitrosothiols as active intermediates. J. Pharmacol. Exp. Ther. 218:739-749.

24. Stuehr, D. J., O. A. Fasehun, N. S. Kwon, S. S. Gross, J. A. Gonzalez, R Levi, and C. F. Nathan. 1991. Inhibition of macrophage and endothelial cell nitric oxide synthase by diphenyleneiodonium and its analogs. FASEB (Fed. Am. Soc. Exp. Biol.) J. 5:98-103.

25. Green, L. C., D. A. Wagner, J. Glogowski, P. L. Skipper, J. S. Wishnok, and S. R. Tannenbaum. 1982. Analysis of nitrate, nitrite, and [15N] nitrate in biological fluids. Anal. Biochem. 126:131-138.

26. Shapiro, H. M. 1988. Practical Flow Cytometry. Second edition. Alan R. Liss, Inc., New York. 129-133.

27. Becker, Y., U. Olshevsky, and J. Levitt. 1967. The role of arginine in the replication of herpes simplex virus. J. Gen. Virol. 1:471-478.

28. Samuel, C. E. 1991. Antiviral actions of interferons; interferon-regulated cellular proteins and their surprisingly selective antiviral activities. Virology. 183:1-11.

29. Beutler, B., and A. Cerami. 1989. The biology of cachectin/TNF: a primary mediator of the host response. Annu. Rev. Immunol. 7:625-655.

30. Bohn, H., R. Beyerle, P. A. Martorano, and K. Schonafinger. 1991. CAS 936, a novel syndonimine with direct vasodilating and nitric oxide-donating properties: effects on isolated blood vessels. J. Cardiovasc. Pharmacol. 18:522-527.

31. Hibbs, J. B., Jr., R. R. Taintor, and Z. Vavrin. 1987. Macrophage cytotoxicity: role for L-arginine deiminase and imino nitrogen oxidation to nitrite. Science (Wash. DC). 235:473-476.
32. Albina, J. E., J. A. Abate, and W. L. Henry, Jr. 1991. Nitric oxide production is required for murine resident peritoneal macrophages to suppress mitogenstimulated T cell proliferation: role of IFN- $\gamma$ in the induction of the nitric oxidesynthesizing pathway. J. Immunol. 147:144-148.

33. Kubes, P., M. Suzuki, and D. N. Granger. 1991. Nitric oxide: an endogenous modulator of leukocyte adhesion. Proc. Natl. Acad. Sci. USA. 88:46514655.

34. Kilbourn, R. G., and O. W. Griffith. 1992. Overproduction of nitric oxide in cytokine-mediated and septic shock. J. Natl. Cancer Inst. (Bethesda). 84:827831 .

35. Cai, W., and P. A. Schaffer. 1991. A cellular function can enhance gene expression and plating efficiency of a mutant defective in the gene for ICPO, a transactivating protein of herpes simplex virus type 1 . J. Virol. 65:4078-4090.

36. Goldstein, D. J., and S. K. Weller. 1988. Factor(s) present in herpes simplex virus type 1-infected cells can compensate for the loss of large subunit of the viral ribonucleotide reductase: characterization of an ICP6 deletion mutant. Virology. 166:41-51.

37. Daikoku, T., N. Yamamoto, K. Maeno, and Y. Nishiyama. 1991. Role of viral ribonucleotide reductase in the increase of dTTP pool size in herpes simplex virus-infected Vero cells. J. Gen. Virol. 72:1441-1444.

38. Lepoivre, M., F. Fieschi, J. Coves, L. Thelander, and M. Fontecave. 1991. Inactivation of ribonucleotide reductase by nitric oxide. Biochem. Biophys. Res. Commun. 179:442-448.

39. Jacobson, J. G., D. A. Leib, D. J. Goldstein, C. L. Bogard, P. A. Schaffer, S. K. Weller, and D. M. Coen. 1989. A herpes simplex virus ribonucleotide reductase deletion mutant is defective for productive acute and reactivatable latent infections of mice and for replication in mouse cells. Virology. 173:276283.

40. Katz, J. P., E. T. Bodin, and D. M. Coen. 1990. Quantitative polymerase chain reaction analysis of herpes simplex virus DNA in ganglia of mice infected with replication-incompetent mutants. J. Virol. 64:4288-4295.

41. Bredt, D. S., and S. H. Snyder. 1989. Nitric oxide mediates glutamatelinked enhancement of cGMP levels in the cerebellum. Proc. Natl. Acad. Sci. USA. 86:9030-9033.

42. Ignarro, L. J. 1991. Signal transduction mechanisms involving nitric oxide. Biochem. Pharmacol. 41:485-490.

43. de la Maza, M. S., P. A. Wells, and C. S. Foster. 1989. Cyclic nucleotide modulation of herpes simplex virus latency and reactivation. Invest. Ophthalmol. \& Visual Sci. 30:2154-2159.

44. Leib, D. A., K. C. Nadeau, S. A. Rundle, and P. A. Schafer. 1991. The promoter of the latency-associated transcripts of herpes simplex virus type 1 contains a functional cAMP-response element: role of the latency-associated transcripts and cAMP in reactivation of viral latency. Proc. Natl. Acad. Sci. USA. $88: 48-52$.

45. Sawtell, N. M., and R. L. Thompson. 1992. Herpes simplex virus type 1 latency-associated transcription unit promotes anatomical site-dependent establishment and reactivation from latency. J. Virol. 66:2157-2169.

46. Tenser, R. B., K. A. Hay, and W. A. Edris. 1989. Latency-associated transcript but not reactivatable virus is present in sensory ganglion neurons after inoculation of thymidine kinase-negative mutants of herpes simplex virus type 1 . J. Virol. 63:2861-2865.

47. Leib, D. A., C. L. Bogard, M. Kosz-Vnenchak, K. A. Hicks, D. M. Coen, D. M. Knipe, and P. A. Schaffer. 1989. A deletion mutant of the latency-associated transcript of herpes simplex virus type 1 reactivates from the latent state with reduced frequency. J. Virol. 63:2893-2900.

48. Aimi, Y., M. Fujimura, S. R. Vincent, and H. Kimura. 1991. Localization of NADPH-diaphorase-containing neurons in sensory ganglia of the rat. $J$. Comp. Neurol. 306:382-392.

49. Verge, V. M. K., Z. Xu, X. Xu, Z. Wiesenfeld-Hallin, and T. Hokfelt. 1992. Marked increase in nitric oxide synthase mRNA in rat dorsal root ganglia after peripheral axotomy: in situ hybridization and functional studies. Proc. Natl. Acad. Sci. USA. 89:11617-11621.

50. Lowenstein, C. J., C. S. Glatt, D. S. Bredt, and S. H. Snyder. 1992. Cloned and expressed macrophage nitric oxide synthase contrasts with brain enzyme. Proc. Natl. Acad. Sci. USA. 89:6711-6714. 